Originally published in Canadian Journal of Philosophy, Volume. 36, No. 1, March 2006: 1-24. (Received December 2003; Revised August 2004). It is also chapter 2 of my A Future for Presentism (Oxford University Press, 2006)

(C) Craig Bourne

\title{
A Theory of Presentism
}

\section{I: The Parameters of the Problem}

Most of us would want to say that it is true that Socrates taught Plato. According to realists about past facts ${ }^{\mathrm{i}}$, this is made true by the fact that there is, located in the past, i.e., earlier than now, at least one real event that is the teaching of Plato by Socrates. Presentists, however, in denying that past events and facts exist ${ }^{\mathrm{ii}}$ cannot appeal to such facts to make their past-tensed statements true. So what is a presentist to do?

There are at least three conditions that would ideally be met in a satisfactory solution to this problem:

a) It must preserve our views about which statements are true and which false

b) It must be transparent what the truthmakers are for those statements

c) It must explain the truth-value links between various times.

I shall survey two different families of proposals for the presentist's truthmakers, recent examples of each being advocated by Craig (2003) and Ludlow (1999), and show that they fail at least one of these three conditions. This is not entirely negative, for it shows us what an adequate solution to the problem would look like. I go on to show where presentists can find suitable objects that satisfy these conditions, and in this way give a clear statement of presentism, something that is lacking in the literature. ${ }^{\mathrm{iii}}$ 
Originally published in Canadian Journal of Philosophy, Volume. 36, No. 1, March 2006: 1-24. (Received December 2003; Revised August 2004). It is also chapter 2 of my A Future for Presentism (Oxford University Press, 2006)

(C) Craig Bourne

\section{II: Priorian Presentism}

The truth of our statements depends on the way the world is: contingent truths require truthmakers. Everyone should agree with this. What people may disagree about is what truthmakers are. But so long as we all agree that truths depend in some way on the contents of the world (whether they are states of affairs, as in Armstrong's work (e.g., his (1997)) or particulars, as in Lewis's (2003)), then that is enough to generate the concerns of this paper. ${ }^{\text {iv }}$ Thus, given that there are true past-tensed statements, these too require truthmakers. But where in the presentist's world are these to be found? An obvious response is to say that, since only the present exists, these truthmakers are to be found in the present. But what sort of truthmakers could these be?

Suppose we take our cue from Arthur Prior, and use the tense operators, $\mathbf{P}, \mathbf{N}$ and $\mathbf{F}$ (read 'It was the case that', 'It is (now) the case that', and 'It will be the case that', respectively), to pick up the tense of an interior tensed proposition. However complex the tense of the initial proposition, it can be analysed as a basic present-tensed interior proposition together with the appropriate iteration of the tense operators. Since the interior proposition is always present-tensed, there is a redundancy in the use of the operator $\mathbf{N}$ to signify the present tense. This leaves only the $\mathbf{F}$ and $\mathbf{P}$ operators as non-superfluous; we can always drop $\mathbf{N}$ when it appears outside the scope of $\mathbf{P}$ or $\mathbf{F}$ (see Kamp (1971); McArthur (1976)). Because of this, Prior held a 'redundancy theory of the present' (Prior (1957, 9-10); (1967, 8-10, 14-15); (1968a, 17-23); (1968b, 101)): everything that is presently true, is true simpliciter; $\mathbf{N}$ is superfluous in the same way as 'It is true that' is redundant according to the redundancy theory of truth. Indeed, he says 'reality consists in the absence of a qualifying prefix' (1970).

However, this is not to say (pace Tooley $(1997,166)$ ) that we should not think of it as being there for, according to Prior: 
Originally published in Canadian Journal of Philosophy, Volume. 36, No. 1, March 2006: 1-24. (Received December 2003; Revised August 2004). It is also chapter 2 of my A Future for Presentism (Oxford University Press, 2006)

(C) Craig Bourne

'Socrates taught Plato' $(\mathbf{P} p)$

means

'It is now the case that Socrates taught Plato' $(\mathbf{N P} p)$,

where $p$ is the proposition that Socrates is teaching Plato. This has to be correct because it is a present truth that Socrates taught Plato. Thus, the tacit presence of an $\mathbf{N}$ outside the scope of all other operators implies that all tensed propositions are present-tensed; that is, implies, e.g., that the proposition that $\mathbf{F P} p$ is the proposition that NFP $p$; and the first stage of the presentist agenda to reduce past- and future-tensed propositions to present-tensed propositions is easily and naturally achieved.

But the essential question is: what makes such truths true? What are the constituents of the facts that make them true? Prior denies that these questions need answering: for Prior, there is nothing more to say about the nature of time than is said by a perspicuous tense logic (e.g., Prior (1996, 45)). Nevertheless, I (with others, e.g., Smith (1987, 188-191); Tooley (1997, 166-7); Le Poidevin (1998, 38-39)) feel more needs to be said, especially since the issue of truthmaking is independent of the theory of truth: truthmaking arises just as much for deflationary theories of truth as it does for the correspondence theory (as Lewis (2001) and Smith (2003) show). Thus, even if Prior adopts a deflationary theory of truth (and the present) this will not help him avoid the issue of truthmaking; he still needs to say more.

But if we press for an ontology, Prior is ultimately left in an uncomfortable position on one of the prongs of a dilemma. For given his doctrine that propositions are themselves 'logical constructions' out of the objects they are about (Prior (1971, chp1)), how is it possible for the proposition that Socrates taught Plato to be true? Which particulars can be invoked as the constituents of such a fact? Not Socrates or Plato - they don't exist. Nor can we invoke a present past-Socrates - what a mysterious object that would be! The alternative 
Originally published in Canadian Journal of Philosophy, Volume. 36, No. 1, March 2006: 1-24. (Received December 2003; Revised August 2004). It is also chapter 2 of my A Future for Presentism (Oxford University Press, 2006)

(C) Craig Bourne

is to invoke the primitive present fact that Socrates taught Plato. But without being able to say how this fact is structured (for its constituents are certainly not Socrates or Plato), this move is far from satisfactory. Thus either option leaves us with an obscure ontology.

We might think that these are just problems peculiar to Prior's position and of which later presentists must surely have said something satisfactory. But it appears not. Craig (2003) carries on in the same vein. He claims that reference to past objects is possible, since "the proper name "Socrates" expresses an individual essence of Socrates rather than denotes nonconnotatively the actual object Socrates and so does not require Socrates to exist in order for the name to refer' (395). This move, following Plantinga's work on proper names (e.g., Plantinga (1974, 71-81; 137-44; 149-63)), would allow propositions like Socrates taught Plato to be about Socrates and Plato because 'Socrates' and 'Plato' express the essences of Socrates and Plato, and thus refer to them. Now, this sounds incomprehensible to those who subscribe to the view that in order for genuine reference to an object to take place, the object must exist: for according to this view, if Socrates does not exist, 'Socrates' does not refer. But Craig is at pains to draw a distinction between 'reference' and 'correspondence' (394). Correspondence is a relation between world and word and thus requires an object to fall under a name; but reference, we are told, doesn't, since it has 'to do with how terms serve to pick out individuals' (395), something which, it is claimed, doesn't require the existence of the individual. But even if we concede this, it hardly addresses the question of which objects are required for truthmaking, a quite separate issue. If it isn't the concrete object that figures in truthmaking, is it the 'individual essences' expressed by the proper names, essences of objects which exist even though the concrete objects themselves don't? No, for whatever these 'individual essences' are supposed to be, Craig uses them only to argue for the possibility of 'reference' to past objects, not in order to spell out the truthmakers for pasttensed propositions. So what are we left with? For Craig, what makes the proposition that Socrates taught Plato true is the 'tensed fact' (400) that Socrates taught Plato. End of story. 
Originally published in Canadian Journal of Philosophy, Volume. 36, No. 1, March 2006: 1-24. (Received December 2003; Revised August 2004). It is also chapter 2 of my A Future for Presentism (Oxford University Press, 2006)

(C) Craig Bourne

And quite literally so, because nothing more is said about this fact. It certainly cannot have Socrates and Plato as constituents (regardless of whether 'reference' can be made to them), since it is a present fact that Socrates taught Plato and, presently, they don't exist. And it is no good complaining that they did exist, because we want to know what does exist to make the proposition true now. (Note that this is not the unjustifiable requirement that what makes propositions true at a particular time must also be located at that time; since what makes the proposition that Socrates taught Plato true now, according to the tenseless view, is something located in the past, and this seems an entirely reasonable view. The requirement is rather that there be something in existence to make the proposition true; so this cannot be something involving Socrates and Plato, for the presentist, regardless of whether they did exist.) We are simply not told what the constituents of these facts are or how they are structured. It seems that no real progress has been made on this issue with this version of presentism since Prior's work.

But the view that the present contains within it all of the facts required to make past-, present- and future-tensed propositions true creates another, less obvious, concern. We can represent times as sets of present-tensed propositions. Suppose $p$ is a true present-tensed proposition. Now, merely from considering the truth-value links which must hold across times, the following set of true present-tensed propositions must also hold of that time: $\{p$, $\mathbf{F P} p, \mathbf{P F} p, \ldots\} .^{\mathrm{v}}$ But what guarantees that a later time preserves these links? Given the present time represented by $\{p, \mathbf{F P} p, \mathbf{P F} p, \ldots\}$, there must be a later time represented by $\{\mathbf{P} p$, $\mathbf{P F P} p, \mathbf{P P F} p, \ldots\}$. But how can a Priorian Presentist even guarantee this, let alone explain it? Of course, $\mathbf{P F P} p$ must hold in the future, if $p$ holds presently: every adequate theory of time must have this as a consequence or be rejected. But there is no mechanism in this version of presentism to guarantee it. It is no good just appealing to the tense logic and then interpreting this in a deflationary way, since, as noted above, this semantic issue does not address the ontological issues at stake. The ontology, at least as far as Craig is concerned, is such that the 
Originally published in Canadian Journal of Philosophy, Volume. 36, No. 1, March 2006: 1-24.

(Received December 2003; Revised August 2004). It is also chapter 2 of my A Future for

Presentism (Oxford University Press, 2006)

(C) Craig Bourne

present time is comprised of certain tensed facts, including those about what will happen and what has happened. We can add that all times are contingent and distinct entities. But then it follows, if we take the Humean stance, that the truth-value link cannot be guaranteed by any necessary connections between such times or the tensed facts of which they are comprised (at least at the ontological level of tensed facts, if not the semantic level of tense logic). Furthermore, for that matter, there cannot be any transtemporal relations to link times together on this view: other times don't exist; and it is hard to see how the ontological content of the present time can in itself legislate how other distinct entities, other times, can be comprised. Yet somehow it must - for if the content of the present time does not legislate this, what, according to this view, does? - since it is incredible to think that there could be missing tensed facts from, or additional tensed facts in, various times. The truth-value links have somehow to be a feature of how the facts are structured (as they are on the tenseless theory of time, for example, and as they are on the view I present below). But because no mechanism is in place to preserve the truth-value links and the possibility of a violation of them is opened up, this version of presentism should be rejected. ${ }^{\mathrm{vi}}$

\section{III: Reductive Presentism}

A second shot at the thought that the present itself can supply all of the required truthmakers is the Reductive version of presentism. Ludlow (1999, chp.9) is the most recent substantial work on time that advances this view, and Le Poidevin (1991) (a tenseless theorist) recognises this option:

What makes a certain statement about the past true ... is the evidence that at present exists. ... This is possible in virtue of the fact that there are present facts which derive their character from causal connection with past states of affairs, and which determine (at least to some 
Originally published in Canadian Journal of Philosophy, Volume. 36, No. 1, March 2006: 1-24. (Received December 2003; Revised August 2004). It is also chapter 2 of my A Future for

Presentism (Oxford University Press, 2006)

(C) Craig Bourne

extent) the character of the future (37) ... [T]his is essential to the ... (presentist's) position.

And:

The extent to which the principle of bivalence is violated by statements about the past or future depends, for [the presentist], upon how much causal determinism he is prepared to allow. In a fully deterministic universe ... all future- and past-tensed statements have a determinate truthvalue, as this is guaranteed by present fact. But in an indeterministic universe ... many statements about the future must for [presentism] lack a truth-value. (38)

Although it is obvious from the above discussion that, contra Le Poidevin, this story is not 'essential to the [presentist's] position', it is a position that has been held for a variety of reasons (see, e.g., Łukasiewicz $(1970,127-128)$, and Wheeler $(1978,41)$, who thinks that the two-slit experiment in quantum physics vindicates this conception). But it is not a position which has been fully endorsed by any serious philosopher, although, of course, Dummett has played with this view for years (see Dummett (1969) and his latest (2003)). Ludlow $(1999,162)$ claims that although this position is not 'an inevitable consequence of the A-theory', it is 'a possible avenue of investigation'. So, although this is only a tentative endorsement, it is important to briefly show how just a short walk down this supposed avenue reveals it to be more of a cul de sac.

There are two broad categories of theories of laws of nature, which I shall label 'Humean' and 'non-Humean'. Consider the Humean theory, which states that laws consist in nothing more than: whenever there is an $F$, there is a $G$, i.e., $(\forall x)(F x \supset G x)$. The first issue to address here is the 'whenever' quantifier. If it just ranges over times that exist (i.e., the present time!), then any present conjunction of $F$ with $G$ will constitute a law, which is unsatisfactory. But, more damagingly, if it is restricted to times that exist (the present time), then laws cannot do the job for which they were intended. For according to this account, they do not extend beyond the present, and thus cannot determine the truth-values of statements 
Originally published in Canadian Journal of Philosophy, Volume. 36, No. 1, March 2006: 1-24. (Received December 2003; Revised August 2004). It is also chapter 2 of my A Future for Presentism (Oxford University Press, 2006)

(C) Craig Bourne

about the past and the future. We should, then, take it that 'whenever' ranges over present times as well as those that have existed and will exist. The problem now is: what makes it true that all Fs are, have been, and will be Gs? For there is nothing we could appeal to in the present. We certainly can't appeal to deterministic laws of nature to ground what has happened and what will happen, since this just lands us in a circle, for the whole problem was to find something in the present that could ground what that law is. And the present state of the universe by itself cannot determine what has happened and what will happen because the present state of the universe is compatible with infinitely many different mutually contradictory pasts and futures: it is only the state of the universe at a given time together with deterministic laws of nature which can determine what has happened and what will happen. But there is nothing in the reductive presentist's world which can ground such laws. It is not as if a law can be seen as an extra ingredient in the present, which can help determine one course of history over another, for remember that we are talking about a Humean conception of law, and according to this conception, there is nothing more, ontologically speaking, to a law over and above what does actually happen. This leads us to consider an alternative option, namely to appeal to primitive facts: things just did and will occur in this sort of regularity. But this then renders the excursion into Reductive Presentism entirely redundant if we adopt primitive facts: we may as well be Priorian Presentists. Thus, a Humean account of laws will not give Reductive Presentists what that they would hope for.

What about non-Humean accounts? Suppose we thought that laws of nature are some kind of necessary connection between universals. According to Armstrong, the law that $F \mathrm{~s}$ are $G$ s is some sort of necessitation relation $N$ between the universals $F$-ness and $G$-ness. $N(F, G)$ is a contingent nomic necessity that may not hold across all possible worlds, but if it actually holds, then $N(F, G) \Rightarrow(\forall x)(F x \supset G x)$. For various reasons, Armstrong $(1983,86-99)$ argues that $N(F, G)$ is a first-order relational universal that is instantiated by particular states of affairs $F a$ and $G a$. Furthermore, according to Armstrong's Principle of Instantiation (e.g., 
Originally published in Canadian Journal of Philosophy, Volume. 36, No. 1, March 2006: 1-24. (Received December 2003; Revised August 2004). It is also chapter 2 of my A Future for Presentism (Oxford University Press, 2006)

(C) Craig Bourne

$(1983,82))$ universals must be instantiated in order to exist. It follows that given that there are only present states of affairs in the Reductive Presentist's world, any instantiation of a law can only take place in, and be true of, the present. Thus such laws of nature cannot tell us about what happens at other times, and thus cannot ground determinate truth-values for pastor future-tensed statements. (This is particularly problematic given Armstrong's view that the necessitation relation does not supervene on the state of the world, and can change in what it relates from world to world. For even if $N(F, G)$ holds of the present time, there is nothing to say it will hold across all past and future times. Yet that was what the Reductive Presentist hoped the necessitation - although it is hard to see how we can still call it 'necessitation' given these considerations - would guarantee.)

This well known and well worked out non-Humean theory was worth mentioning in order to illustrate the general problem with which Reductive Presentists have to deal: how can the laws reach beyond the present? There are, of course, non-Humean accounts that argue that laws can exist without being so instantiated (e.g., Tooley (1977); Mellor (1980)). But a presentist who appealed to these accounts of laws of nature would either have to find something in the present to ground these laws - and it's difficult to see what this could be or they must appeal to facts outside the present, in which case they've conceded that not all of the truthmakers can be found in the present, which was their initial contention. The notion of determinism will not help the presentist on the issue of securing determinateness of truthvalue.

Needless to say, Reductive Presentism cannot have determinate truth-values in an indeterministic world. Yet, even in an indeterministic world, we still want to say that at least past-tensed statements have determinate truth-values. We want to say that it is either true or false that a certain brontosaurus had two plants for breakfast, regardless of whether there are any traces of this fact in the present, and regardless of whether the present state of the 
Originally published in Canadian Journal of Philosophy, Volume. 36, No. 1, March 2006: 1-24.

(Received December 2003; Revised August 2004). It is also chapter 2 of my A Future for

Presentism (Oxford University Press, 2006)

(C) Craig Bourne

universe and the laws of nature can determine this fact. To confuse determinateness with determinism is an offence. Reductive Presentism thus violates condition (a) of section $\mathbf{I}$.

Furthermore, Reductive Presentism, however much it initially seems to, doesn't in fact meet the truth-value links problem. First, consider Russell's hypothesis (1921, 159-60): what is to say that the world has not just come into existence complete with fossil records, memories, and other such causal traces? Russell intended this to illustrate the limitations of our knowledge, but pre-theoretically, it seems like a genuine possibility for how the world could be. Suppose it is true, then Reductive Presentism gives the wrong answers, for it states that certain past-tensed statements are true when they shouldn't be. Of course, nobody thinks that hypothesis is true; but Russell's hypothesis doesn't have to be actually true to cause trouble; that it is true that is it possible is enough to show that Reductive Presentism has a problem accounting for truth-value links. And we couldn't rule out Russell's hypothesis by appealing to actual laws of nature that wouldn't allow for such a complex environment in such a short space of time, for as I have argued above, the grounding of those very laws is called into question on the Reductive view. That is, in a nutshell, truth-value links are supposedly underpinned by causal links: present facts are effects of previous causes and themselves causes of later effects. But this relies on what it is in the present that grounds this causal link: for it to be true that a given fact is an effect of a previous cause, we need the present fact that it is the effect of a previous cause to make this true, since without this fact there is nothing to link the supposed 'effect' to anything that came before, or the supposed 'cause' to anything that comes after. (And we certainly need this, given the many different pasts and futures compatible with the present state of the universe.) But what sort of fact could this be? Taking it as a primitive present fact lumbers us with the Priorian Presentist's facts and all their attendant problems. We are no better off after all. 
Originally published in Canadian Journal of Philosophy, Volume. 36, No. 1, March 2006: 1-24. (Received December 2003; Revised August 2004). It is also chapter 2 of my A Future for Presentism (Oxford University Press, 2006)

(C) Craig Bourne

We now have an appreciation of what any successful version of presentism must hope to achieve, and the pitfalls it must avoid. The version of presentism I am about to propose meets these conditions. It also meets the challenges that some (e.g., Oaklander (2002); (2003)) throw down for presentism to tackle, namely how presentists can help themselves to the notion of earlier than without having to invoke real relata, and how presentism can distinguish the past from the future. It should also be attractive to those who see close analogies between time and modality, and who prefer ersatz theories of possible worlds (such as Adams's (1974)) over genuine modal realism (such as Lewis's (1986)), for the position I will defend is essentially this: all of us should agree that Socrates taught Plato, i.e., that the proposition that Socrates is teaching Plato was, at some time, true. This, to most people, is so obvious as to not be worth stating. So I ask them to keep this in mind during the more technical exposition of the position which is about to follow. For I say we should take the 'i.e.' seriously; that is, that what makes it true that Socrates taught Plato is the existence of a proposition according to which this is the case for some time in the past, where a time is a set of propositions representing the other truths about what happens at that time. For obvious reasons, I shall call this position 'Ersatzer Presentism'.

\section{$\underline{\text { IV: Ersatzer Presentism }}{ }^{\text {vii }}$}

a) An improvement over Prior's Presentism: e-propositions and u-propositions

I go some way with Prior ((1967, 79-82); (1968a, 122-6)) in constructing times from certain sets of present-tensed propositions. ${ }^{\text {viii }}$ However, my account differs in important respects. According to Prior, the present moment should be equated with the conjunction of all those propositions which are presently true, i.e., true simpliciter; and generalising, he equates any 
Originally published in Canadian Journal of Philosophy, Volume. 36, No. 1, March 2006: 1-24.

(Received December 2003; Revised August 2004). It is also chapter 2 of my A Future for

Presentism (Oxford University Press, 2006)

(c) Craig Bourne

time with a conjunction of all those present-tensed propositions which would be true at that time.

My conception differs, first, in that I distinguish present-tensed propositions that contain either $\mathbf{P}$ or $\mathbf{F}$ operators, which I shall call 'embedded propositions' (e-propositions), from those that do not, which I shall call 'unembedded propositions' ( $u$-propositions). (Compare, for example, the $e$-proposition: It is now the case that it was the case that Socrates is sitting (i.e., $\mathbf{N P} p$ ), with the $u$-proposition: It is now the case that Socrates is sitting (i.e., $\mathbf{N} p$ ), or simply: Socrates is sitting (i.e., $p$ ).)

As we have seen, Priorian Presentism required the present to be equated with $e$ propositions in order for the present to supply all of the truths we believe there are, but that it was rather mysterious what the truthmakers were for these propositions, and neither could it account for the truth-value links between the different times. The theory to be developed avoids these difficulties.

\section{b) Defining times, and the E-relation}

I propose we construct times using maximally consistent sets of $u$-propositions, which intuitively we can see as those $u$-propositions that are true at that time. These propositions I take to give a complete, maximally specific description of what is true at that time. But more needs to be added: they, at least, need to be ordered by an 'earlier than' relation (what I will call an ' $E$-relation'), in order for the ersatz time series to be structurally similar to a real time series, so it can be taken to be a sufficient substitute. That is, we can introduce the ordered triple $\langle\mathbf{T}, E, t\rangle$, where $\mathbf{T}$ is a set, $E$ is a relation on $\mathbf{T}$, and $t \in \mathbf{T}{ }^{\text {ix }}$ Intuitively, $\mathbf{T}$ is the set of times, $E$ is the 'earlier than' relation, and $t$ is a particular time. Times I take to be more than sets of present-tensed propositions: first, they consist of sets of $u$-propositions; second, they also contain a 'date'. That is, I take times (at least for the time being) to be ordered pairs of 
Originally published in Canadian Journal of Philosophy, Volume. 36, No. 1, March 2006: 1-24. (Received December 2003; Revised August 2004). It is also chapter 2 of my A Future for Presentism (Oxford University Press, 2006)

(C) Craig Bourne

the form $t=\langle\mu, n \in \mathbb{R}\rangle$, where $\mu$ is a set of $u$-propositions and $n \in \mathbb{R}$ is the date. Times can now be defined as those ordered pairs of the form $t=\langle\mu, n \in \mathbb{R}\rangle$ that are members of the class of sets of ordered pairs of the form $t=\langle\mu, n \in \mathbb{R}\rangle$ that are $E$-related. Actual times are those times that are members of the class of times that are actually E-related. (What this amounts to is explained below.)

Defining times in the way I have done requires us to alter our terminology slightly. Lewis $(1986,140)$ has complained that ersatzism concerning possible worlds commits us to saying that since worlds are, say, sets of propositions, the concrete object that we are part of - 'the world', speaking with the vulgar - cannot be said to be a world. Similarly, since, according to Ersatzer Presentism, times are abstract objects, the present time is not something we inhabit. But rather than introduce a new term, or typescript, for what I am calling 'times', I prefer to keep this useful terminology. The only differences it makes are that we must be said to inhabit the concrete realisation of the present time, and that Ersatzer Presentism is the view not that only one time exists, but that only one time has a concrete realisation. This is a mere nominal difference, equivalent to saying that presentists do not believe in any times other than the present; and all is as it should be.

The $E$-relation is not the genuine earlier than relation since it does not relate spatiotemporal objects, but it does represent the earlier than relation in the way it relates times. The properties of the $E$-relation match whatever we take to be the properties of the genuine earlier than relation. This allows presentists to have a time series related by 'earlier than' without being committed to the existence of real, or rather, concretely realised relata, something anathema to presentism. Ersatzer Presentism thus bypasses the problems that other presentists get into when they do not take such relations as basic, and try to define them in terms of tenses (see, e.g., Oaklander (2002); Mellor (2003, 236-237)).

Various metrical and topological features of time can be represented in the structure of the abstract objects. For example, if we take time to be linear, the E-relation will have, 
Originally published in Canadian Journal of Philosophy, Volume. 36, No. 1, March 2006: 1-24.

(Received December 2003; Revised August 2004). It is also chapter 2 of my A Future for

Presentism (Oxford University Press, 2006)

(C) Craig Bourne

among other things, the properties of being irreflexive, asymmetric and transitive; if it is circular, it will be an equivalence relation, and times form an equivalence class; if time is continuous, the times are assigned real numbers as dates; if discrete, then only those times that have dates $n \in \mathbb{Z}$ will be realised; if it is infinite in both directions from the present, then the dates will have the standard order type of infinite time $\left(\omega^{*}+\omega\right)$; if time is circular then the dates will be of the form of a periodic function (for some period with value $\mathrm{P}, t(x+\mathrm{P})=t(x)$ ), and so on.

But despite the fact that these properties of time can be represented in this way, presentism has a very good reason for adopting a branching topology; that is, where the $E$ relation is a one-many relation in the direction from the present to future (the direction in which the dates increase in magnitude), but only a one-one relation in the direction from the present to the past (the direction in which the dates decrease in magnitude). The reason is simple: we all need a way of distinguishing the past from the future. Because presentism treats the past and the future as ontologically on a par, in the sense that it denies that there are any concrete truthmakers located there, the branching structure of times is an obvious way in which presentism can differentiate between past and future. Furthermore, it accounts for the platitude that the past is 'fixed' and the future is 'open', something that any good theory of time should. Thus, if we follow my proposal, presentism does have at its disposal means for distinguishing the past from the future.

c) Truth-conditions, truthmakers, truth-at-a-time, and truth simpliciter

I also distinguish truth-at-a-time from truth simpliciter. ${ }^{\mathrm{x}}$ Truth simpliciter is an absolute, not time-relative, notion, whereas truth-at-a-time is time-relative: all propositions at a time are true relative to it, but only those propositions which are true at the present time are true 
Originally published in Canadian Journal of Philosophy, Volume. 36, No. 1, March 2006: 1-24. (Received December 2003; Revised August 2004). It is also chapter 2 of my A Future for Presentism (Oxford University Press, 2006)

(C) Craig Bourne

simpliciter. So, where the propositions involved are any atomic propositions, be they from propositional or predicate calculi, we have:

(1) Socrates is sitting is true-at-a-time iff there is a time, i.e., E-related order pair $<\mu, n \in \mathbb{R}>$ such that $\mu$ includes the $u$-proposition that Socrates is sitting, i.e., $p$ is true-at-a-time $\langle\mathbf{T}, E,\langle\mu, n \in \mathbb{R}>>$ iff $p \in \mu$.

And similarly,

(2) $\quad \sim p$ is true-at-a-time $\langle\mathbf{T}, E,\langle\mu, n \in \mathbb{R}>>$ iff $p \notin \mu$.

(3) $\quad p \& q$ is true-at-a-time $\langle\mathbf{T}, E,\langle\mu, n \in \mathbb{R}>>$ iff $p, q \in \mu$.

Whereas:

(4) Socrates is sitting is true simpliciter iff Socrates (i.e., an actual, concrete, flesh and blood Socrates) is presently sitting.

Furthermore, it is not only present-tensed $u$-propositions that can be true simpliciter; past-tensed propositions can be too. The difference is that whereas present-tensed $u$ propositions are made true simpliciter iff corresponding actual concrete facts are presently realised, past-tensed propositions are made true simpliciter by something entirely different.

It was the case that $p$ is true simpliciter iff $p$ is a member of a set $\mu$ of $u$-propositions that is the first element of an order pair $\left\langle\mu, n_{i} \in \mathbb{R}>\right.$ actually $E$-related to the presently instantiated ordered pair $\left\langle v, n_{j} \in \mathbb{R}\right\rangle$, where $v$ is the set of $u$-propositions that is true simpliciter, and $n_{i}<n_{j} .{ }^{\mathrm{xi}}$ 
Originally published in Canadian Journal of Philosophy, Volume. 36, No. 1, March 2006: 1-24.

(Received December 2003; Revised August 2004). It is also chapter 2 of my A Future for

Presentism (Oxford University Press, 2006)

(C) Craig Bourne

Note that the 'actual' here is not superfluous: it has a technical use. Since time has a branching structure, then time actually has a branching structure and all possible times on each of these branches are in some sense of 'actual' actually E-related. Yet I require only some times as truthmakers for past- and future-tensed statements, namely those that correspond to what we would ordinarily want to call the actual history of the world. Thus, when I use the phrase 'actually $E$-related' I mean that there is a time which is $E$-related to the time that is true simpliciter, i.e., that is actually concretely realised. This grounds which $E$ related branch we should use for finding truthmakers for past-tensed statements, since only one $E$-related branch is accessible from the concretely realised time in the direction towards the past.

In short we have the following story about truthmakers:

- What makes $u$-propositions true simpliciter are actually realised concrete facts

- What makes past-tensed propositions true simpliciter are actually E-related ordered pairs of $u$-propositions and dates.

- What makes $p$ true-at-time- $t$ is the fact that $p \in \mu$, where $t=\langle\mu, n \in \mathbb{R}\rangle$.

It now remains to complete the story by dealing with quantification. ${ }^{\text {xii }}$

$\mathbf{P} \forall x F x$ is true at $\langle\mathbf{T}, E, t\rangle$ (and is true simpliciter iff the set of propositions at $t$ is true simpliciter) iff $\forall x F x$ is true at some time $E$-related to $t$, where $\forall x F x$ is true-at-a-time $\langle\mathbf{T}, E,\langle\mu, n \in \mathbb{R}\rangle\rangle$ iff $\forall x F x \in \mu$.

$\mathbf{P} \exists x F x$ is true at $\langle\mathbf{T}, E, t\rangle$ (and is true simpliciter iff the set of propositions at $t$ is true simpliciter) iff $\exists x F x$ is true at some time $E$-related to $t$, where $\exists x F x$ is true-at-a-time $\langle\mathbf{T}, E,\langle\mu, n \in \mathbb{R}\rangle\rangle$ iff $\exists x F x \in \mu$. 
Originally published in Canadian Journal of Philosophy, Volume. 36, No. 1, March 2006: 1-24. (Received December 2003; Revised August 2004). It is also chapter 2 of my A Future for Presentism (Oxford University Press, 2006)

(C) Craig Bourne

As noted in fn.ii, presentists should read the existential quantifier tenselessly. I also take it that ' $(\exists x) F x$ ' should be read in the standard objectual way. The quantified propositions $\exists x F x$ and $\forall x F x$ themselves are to be given their standard truth-conditions in terms of the satisfaction of the incomplete proposition $F x$. Despite being taken tenselessly, the proposition that $(\exists x) F x$ might change truth value from time to time because of the continually changing concrete facts and subsequent change in the domain of quantification. Note that the objects that at one time satisfy $F x$ need not remain in existence for a quantified proposition within a tense operator to be true. ${ }^{\text {iv }}$

d) The future

An interesting question that arises for Ersatzer Presentism is accounting for future-tense propositions. Can the proposition that It will be the case that $p$ be true simpliciter? According to this theory,

It will be the case that $p$ is true simpliciter iff $p$ is a member of a set $\mu$ of $u$ propositions that is the first element of an order pair $\left\langle\mu, n_{i} \in \mathbb{R}\right\rangle$ actually $E$-related to the presently realised ordered pair $\left\langle v, n_{j} \in \mathbb{R}\right\rangle$, where $v$ is the set of $u$-propositions that is true simpliciter, and $n_{i}>n_{j}$.

However, it will be that $p$ is neither determinately true simpliciter nor determinately false simpliciter, when $p$ is contingent, given that, as of the present, no one future branch is actual. Furthermore, consider the truth-conditions for future-tensed quantified statements:

$\mathbf{F}(\forall x) F x$ is true at $\langle\mathbf{T}, E, t\rangle$ (and is true simpliciter iff the set of propositions at $t$ is true simpliciter) iff $(\forall x) F x$ is a member of some $\mu$ element of times later than $t$ (understood in the ersatz way), where $(\forall x) F x$ is true-at-a-time $\langle\mathbf{T}, E,\langle\mu, n \in \mathbb{R}\rangle>$ iff $(\forall x) F x \in \mu$. 
Originally published in Canadian Journal of Philosophy, Volume. 36, No. 1, March 2006: 1-24.

(Received December 2003; Revised August 2004). It is also chapter 2 of my A Future for

Presentism (Oxford University Press, 2006)

(C) Craig Bourne

$\mathbf{F}(\exists x) F x$ is true at $\langle\mathbf{T}, E, t\rangle$ (and is true simpliciter iff the set of propositions at $t$ is true simpliciter) iff $(\exists x) F x$ is a member of some $\mu$ element of a time later than $t$ (understood in the ersatz way), where $(\exists x) F x$ is true-at-a-time $\langle\mathbf{T}, E,\langle\mu, n \in \mathbb{R}\rangle>$ iff $(\exists x) F x \in \mu$.

Given the branching future, $\mathbf{F}(\forall x) F x$ is only true simpliciter when the proposition that $(\forall x) F x$ is true at all times later than the present, i.e., on all possible branches. And $\mathbf{F}(\exists x) F x$ is only false simpliciter when the proposition that $(\exists x) F x$ is true at no time later than the present, i.e., on no possible branches. That they have determinate truth-values only in these extreme circumstances, however, must only really be treated as a consequence of the branching view, not a criticism of it. But I should discuss here Lewis's (1986) argument against branching time, since it is based on a common misconception it. Lewis writes:

The trouble with branching exactly is that it conflicts with our ordinary presupposition that we have a single future. If two futures are equally mine, one with a sea fight tomorrow and one without, it is nonsense to wonder which way it will be - it will be both ways - and yet I do wonder. The theory of branching suits those who think this wondering makes sense only if reconstrued: you have leave to wonder about the sea fight, provided that really you wonder not about what tomorrow will bring but about what today predetermines. (207-8)

Lewis is wrong, however, to conclude that a branching future commits one to holding 'it will be both ways'. He is confusing the fact that there are many future branches to be realised as of the present time, with the fact that only one of them will be realised. After all, that is the only way to make sense of the claim that future contingent statements have indeterminate truth-values ${ }^{\mathrm{xv}}$ - if it will be both ways, then both of the statements are true. But according to the branching view, future contingents are presently indeterminate precisely because only one branch of the possible branches will get realised, but that there is no branch 
Originally published in Canadian Journal of Philosophy, Volume. 36, No. 1, March 2006: 1-24. (Received December 2003; Revised August 2004). It is also chapter 2 of my A Future for

Presentism (Oxford University Press, 2006)

(C) Craig Bourne

in particular that is presently that branch. Thus it makes good sense to wonder now which of the unrealised branches will become the future. Thus branching does not conflict with our ordinary presupposition that we will have a single future, although it does conflict with the idea that we have a single future. The former presupposition is something we surely do not want to reject - it is close to being a platitude. But it is far from clear that the latter presupposition has such a status, and arguably is contrary to most people's commonsense view of the future: many people think, in a clear-headed way, that pace Lewis, we don't have a single future, but we will have one. And, moreover, this has nothing to do with what is 'predetermined': as already noted above (§III), determinism is neither here nor there on the issue of the determinateness of the future. Lewis's argument is thus far from compelling.

\section{V: Branching time for presentists}

It just remains to fill out the story concerning the branching structure and show how Ersatzer Presentism can account for the truth-value links between times. Consider: 
Originally published in Canadian Journal of Philosophy, Volume. 36, No. 1, March 2006: 1-24. (Received December 2003; Revised August 2004). It is also chapter 2 of my A Future for Presentism (Oxford University Press, 2006) (C) Craig Bourne

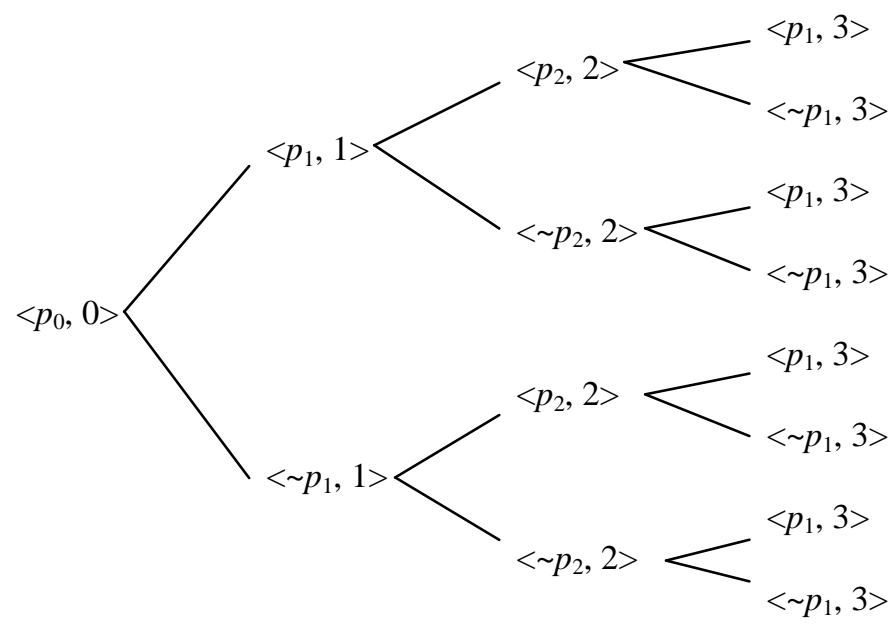

At the present, there is only one past accessible to it and no unique future. The set-up is such that all possible futures are represented and accessible from each node on a particular branch, so whichever time gets realised next will be represented somewhere on one of the future branches accessible from it: the branching structure gives us completeness.

a) A problem with truth-value links?

But a problem arises. Suppose that $p_{0}$ is true simpliciter, i.e., that time $t_{0}$ is presently realised. Now suppose that the proposition $p_{1}$ is made true simpliciter next. What guarantee have we that it is $p_{1}$ at $t_{1}$ that has been realised rather than, say, $p_{1}$ at $t_{3}$ ? If there is nothing to constrain which time is realised, it seems that we are committed to saying that the concrete facts that have just 'become' realise all of these times equally. But if this is the case, then there are branches that state

$$
\left\langle<p_{1}, 1\right\rangle,\left\langle p_{0}, 0\right\rangle>
$$

is the history of the world, whereas others state 
Originally published in Canadian Journal of Philosophy, Volume. 36, No. 1, March 2006: 1-24. (Received December 2003; Revised August 2004). It is also chapter 2 of my A Future for Presentism (Oxford University Press, 2006)

(C) Craig Bourne

$$
\left\langle\left\langle p_{1}, 3\right\rangle,\left\langle p_{2}, 2\right\rangle,\left\langle p_{1}, 1\right\rangle,\left\langle p_{0}, 0\right\rangle\right\rangle
$$

is, whereas others state that

$$
\left\langle\left\langle p_{1}, 3\right\rangle,\left\langle\sim p_{2}, 2\right\rangle,\left\langle\sim p_{1}, 1\right\rangle,\left\langle p_{0}, 0\right\rangle\right\rangle
$$

is, and if $p_{1}$ is true simpliciter, it seems that there is nothing to choose between these options. Something needs to be done to preserve the truth-value links.

The problem here arises because of the sparseness of the concrete present: it is not sufficiently rich to determine everything that needs to be determined in order to defend a plausible view of time. But this is no great news; that's exactly what I have been arguing so far, and precisely the reason for invoking more than the concrete present facts as truthmakers for tensed statements. This was, after all, what confined the previous versions of presentism to an implausible position. But once we remember that Ersatzer Presentists have more artillery at their disposal, this problem has an obvious solution. For according to the theory here proposed, the sets of propositions follow the ordering of the dates; so although the content of the proposition $p_{1}$ is the same wherever it occurs as a member of a time, it is also associated with a date. This allows us to stipulate that when $p_{0}$ is realised at time 0 , the next set to be realised must by definition be a set that is indexed by 1 (or whatever number sequence or metric we choose to be appropriate), and so on. This is no more mysterious than holding that 2nd January follows the 1st January, something that all sides accept. So there is a natural and non-arbitrary way of specifying which time it is that has been realised. The truth-value links remain intact. 
Originally published in Canadian Journal of Philosophy, Volume. 36, No. 1, March 2006: 1-24. (Received December 2003; Revised August 2004). It is also chapter 2 of my A Future for Presentism (Oxford University Press, 2006)

(C) Craig Bourne

\section{b) A further problem with truth-value links for branching time presentists?}

However, there is another potential objection. Suppose that it is $\left\langle p_{1}, 1\right\rangle$ that is realised after $\left\langle p_{0}, 0\right\rangle$, rather than, say, $\left\langle p_{1}, 3\right\rangle$, due to the fact that $\left\langle p_{1}, 1\right\rangle$ is indexed by 1 and $\left\langle p_{1}, 3\right\rangle$ is indexed by 3 , and 1 is the least available number greater than 0 . Now suppose that proposition $p_{2}$ is made true simpliciter by the next concrete facts to 'become'. What guarantee have we that it is the $p_{2}$-set in the history

$$
\left\langle<p_{2}, 2\right\rangle,\left\langle p_{1}, 1\right\rangle,\left\langle p_{0}, 0\right\rangle>
$$

that is realised, rather than the $p_{2}$-set in the history

$$
\left\langle\left\langle p_{2}, 2\right\rangle,\left\langle\sim p_{1}, 1\right\rangle,\left\langle p_{0}, 0\right\rangle>\right.\text { ? }
$$

Indeed, since there is nothing in the present to determine which one is realised (both $p_{2}$-sets are, after all, indexed by 2), it seems that we are committed to saying that both have equal claim to have been realised, and our truth-value links again break down.

This objection again relies on there not being enough in the present to determine which of the sets is realised. But, again, this is not the theory that I am putting forward; there are more facts available to determine which $p_{2}$-set is realised. For once we have in place the fact that it is $\left\langle p_{1}, 1\right\rangle$ that is realised after $\left\langle p_{0}, 0\right\rangle$, there is a fact of the matter as to which branch has been realised, namely the $\left\langle\left\langle p_{1}, 1\right\rangle,\left\langle p_{0}, 0\right\rangle>\right.$ history rather than the $\left\langle\left\langle\sim p_{1}, 1\right\rangle\right.$ $\left\langle p_{0}, 0>>\right.$ history. It follows that it must be the $p_{2}$-set accessible from the $<p_{1}, 1>$ that is the next to be realised, since it is a fact that that branch is realised and not the $\left\langle\sim p_{1}, 1\right\rangle$ branch. 
Originally published in Canadian Journal of Philosophy, Volume. 36, No. 1, March 2006: 1-24.

(Received December 2003; Revised August 2004). It is also chapter 2 of my A Future for

Presentism (Oxford University Press, 2006)

(C) Craig Bourne

This can be represented formally, rather than diagrammatically, by adding an accessibility relation defined over times, and adding a 'positional' element to times. Times are now ordered triples of the form $\langle\mu, n \in \mathbb{R}, \sigma\rangle$, where $\sigma$ is the position of the time in the branching structure, something given by specifying the sequence of times along its past. For discrete time, this can be achieved simply by including the last time realised as the third element (since this time will specify its past, and so on). Thus, for the case of discrete branching time, time $n+1$ has the form $t_{n+1}=\left\langle\mu, n+1, t_{n}\right\rangle$, where $t_{n}=\left\langle v, n, t_{n-1}\right\rangle$, and so on. The accessibility relation $R$ for $\langle\mathbf{T}, E, t, R\rangle$ can be defined as follows: for all times, $t_{n+1}$ is accessible to $t_{n}$ iff $t_{n}$ is a member of $t_{n+1}$, i.e.,

$$
(\forall t)\left(R\left(t_{n+1}, t_{n}\right) \equiv t_{n} \in t_{n+1}\right)
$$

We can also generalise to continuous time. The reason that we must say something slightly different for continuous time is that there is no 'next available date' or 'last time realised' to be the positional element. But all that needs to be said to constrain the order of realisation is first to say that the order of realisation must follow the order of the real numbers as given by the greater than relation. Second, it may not be possible to specify a particular time as the positional element of a time, but it is possible to specify the position using the sequence of times leading up to that time (which I represent as ' $\sigma_{<a}$ '), and then represent times as follows:

$$
t_{a}=\left\langle\mu, a \in \mathbb{R}, \sigma_{<a}>\right.
$$

So generalising to include continuous time, the accessibility relation $R$ for $\langle\mathbf{T}, E, t, R\rangle$ can now be defined as follows: for all times, $t_{b}$ is accessible to $t_{a}$ iff $t_{a}$ is included in the third element of $t_{b}$, i.e., 
Originally published in Canadian Journal of Philosophy, Volume. 36, No. 1, March 2006: 1-24. (Received December 2003; Revised August 2004). It is also chapter 2 of my A Future for Presentism (Oxford University Press, 2006)

(C) Craig Bourne

$$
(\forall t)\left(R\left(t_{b}, t_{a}\right) \equiv\left(\left(t_{a} \subset \sigma_{<b}\right) \&\left(t_{b}=\left\langle v, b \in \mathbb{R}, \sigma_{<b}>\right)\right)\right) .\right.
$$

c) Tying up loose branches: one last objection met

Now that the metaphysics and semantics have been given for Ersatzer Presentism, I should answer one possible objection: Why is it that a certain atomic proposition $p$ appears in a given E-related time if not because it was the case that p? But if this is the explanation, if this is how the story ultimately bottoms out, then how is Ersatzer Presentism any better off than Priorian Presentism?

There are a few things to say in response. First, whether a given proposition appears in a time is simply a brute fact. Or rather, since all possible sets of propositions appear on the branches, it is a necessary truth that such propositions appear in some of the times, and it is a brute fact that one of them gets realised. This is no objection since it is no more mysterious than concrete facts being realised at the times they are according to tenseless theorists. The potential threat of the question comes from explaining why the various times are $E$-related. But on reflection it is more of a toothless suck than a vicious bite. For according to Ersatzer Presentism, what makes It was the case that $p$ true is an actually E-related ordered triple, whereas according to the tenseless theory, what makes it true is an actually earlier thanrelated concrete fact. Now to ask why these ordered triples are actually $E$-related is about as fair as asking why the concrete facts are actually earlier than-related in the tenseless theory, i.e., not at all - they just are. In this sense, then, all theories take it as a brute fact that it was the case that $p$; the advantage over Priorian Presentism is that these other theories have an account of what this fact looks like, be it an E-related abstract structure or an earlier thanrelated concrete one. 
Originally published in Canadian Journal of Philosophy, Volume. 36, No. 1, March 2006: 1-24. (Received December 2003; Revised August 2004). It is also chapter 2 of my A Future for Presentism (Oxford University Press, 2006)

(C) Craig Bourne

\section{VI: The advantages of Ersatzer Presentism}

Ersatzer Presentism, then, can meet the three conditions that any satisfactory account of time should: it allows us to state truths about the past; it wears its ontological commitments on its sleeve, and it ensures that truth-value links are preserved. There are two further advantages. First, it is often argued that there is no substance to the tensed-tenseless debate - that once we recognise the confusion over tensed and tenseless readings of various quantifiers and copulas, the tenseless theorist's 'does exist in the past' is not substantially different from the tense theorist's 'existed' - they are the same theory under different descriptions. I need not show here all the ways in which I think this line of argument is confused, for the charge that the debate is insubstantial certainly cannot be levelled against Ersatzer Presentism, whether or not it affects other versions of presentism. According to Ersatzer Presentism, the constituents of past and future times are not spatio-temporally or causally related objects, unlike past and future times according to the tenseless theory. The constituents of ersatz past and future times are propositions, numbers and sets of propositions and numbers, and so can only have those relations that can hold between sets, propositions and numbers. These conceptions of past and future times are so radically different that it would stretch the meaning of the word 'same' to claim that they are essentially the same theory under different descriptions! Unlike the tenseless theory, according to Ersatzer Presentism, there really is no time like the present.

The second advantage is that many have complained that there is no good motivation for becoming a tense theorist, let alone a presentist. Tooley $(1997,250)$ has argued that before we do commit ourselves to a tensed theory, there is a 'need for metaphysical argument'. Here I claim the argument in favour of Ersatzer Presentism over its rivals is ontological parsimony. The tenseless theory, for instance, postulates appropriately related past and future concrete objects as truthmakers for various tensed statements; but this is 
Originally published in Canadian Journal of Philosophy, Volume. 36, No. 1, March 2006: 1-24. (Received December 2003; Revised August 2004). It is also chapter 2 of my A Future for

Presentism (Oxford University Press, 2006)

(C) Craig Bourne

something Ersatzer Presentism can discard. Neither does Ersatzer Presentism postulate mysterious facts in the present to make past-tensed statements true. Indeed, the discussion indicates that a theory that just rests solely on concretely realised present facts will not adequately account for all the truths we need. So the appeal to more objects other than concretely realised present facts is the necessary concession presentism must make to be viable. But it is still a highly attractive theory if you already believe in abstract objects (propositions, numbers, and sets), which many of us do. Thus it isn't an issue of quantitative versus qualitative parsimony (see Bacon (1995, 87); Lewis $(1973,87)$ for this distinction). The argument is that Ersatzer Presentism is quantitively more parsimonious than the tenseless theory; that is, the set of objects that Ersatzer Presentism postulates is a proper subset of those objects that the tenseless theory postulates. But quantitative savings are still significant: everyone agrees that one can have too much of a good thing. Thus, if you prefer ontologically economical theories without having to live on a shoestring, then Ersatzer Presentism is the theory to adopt. ${ }^{\text {xvi }}$ 
Originally published in Canadian Journal of Philosophy, Volume. 36, No. 1, March 2006: 1-24. (Received December 2003; Revised August 2004). It is also chapter 2 of my A Future for Presentism (Oxford University Press, 2006)

(C) Craig Bourne

\section{References:}

Adams, R.M. 1974. "Theories of Actuality.” Noûs 8 (1974): 211-231. Reprinted in The Possible and the Actual, ed. M.J. Loux. Ithaca: Cornell University Press, 190-209

Armstrong, D.M. 1983. What is a Law of Nature? Cambridge: Cambridge University Press.

---. 1997. A World of States of Affairs. Cambridge: Cambridge University Press.

Bacon, J. 1995. Universals and Property-Instances: The Alphabet of Being. Oxford: Basil Blackwell.

Bigelow, J. 1996. "Presentism and Properties.” In Philosophical Perspectives 10: Metaphysics, ed. J.E. Tomberlin, 1996. Cambridge, MA and Oxford, UK: Blackwell, 35-52.

Bourne, C.P. 2002. "When am I? A tense time for some tense theorists?" Australasian Journal of Philosophy 80 (2002): 359-71.

---. 2004. "Future Contingents, Non-Contradiction, and the Law of Excluded Middle Muddle." Analysis 64 (2004): 122-8.

---. 2006. A Future for Presentism (Oxford: Clarendon Press)

---. 2007. 'Numerical Quantification and Temporal Intervals: a Span-er in the Works for Presentism?', Logique et Analyse, 50 (2007): 303-316

Craig, W.L. 1997. “Is Presentness a Property?” American Philosophical Quarterly, 34 (1997): 27-40.

---. 2000a. The Tensed Theory of Time: A Critical Examination. Dordrecht: Kluwer.

---. 2000b. The Tenselesss Theory of Time: A Critical Examination. Dordrecht: Kluwer.

Dummett, M. 1969. "The Reality of the Past." In his Truth and Other Enigmas. 1978. London: Duckworth, 358-374.

---. 2003. Truth and the Past. Columbia University Press.

Gale, R.M. 1968. The Language of Time. London: Routledge and Kegan Paul.

Kamp, H. 1971. “Formal Properties of 'Now'.” Theoria, 37 (1971): 179-87.

Kripke, S.A. 1963. "Semantical Considerations on Modal Logic.” Acta Philosophica Fennica, 16 (1963): 83-94.

Le Poidevin, R. 1991. Change, Cause and Contradiction. London: Macmillan.

Le Poidevin, R. ed. 1998. Questions of Time and Tense. Oxford: Oxford University Press.

Lewis, D.K. 1973. Counterfactuals. Oxford: Basil Blackwell.

---. 1986. On the Plurality of Worlds. Oxford: Basil Blackwell. 
Originally published in Canadian Journal of Philosophy, Volume. 36, No. 1, March 2006: 1-24. (Received December 2003; Revised August 2004). It is also chapter 2 of my A Future for Presentism (Oxford University Press, 2006)

(C) Craig Bourne

---. 2001. "Forget about the 'Correspondence Theory of Truth'.” Analysis, 61 (2001): 275-280

---. 2003. “Things qua Truthmakers.” In Real Metaphysics: Essays in honour of D.H. Mellor, ed. H.

Lillehammer and G. Rodriguez-Pereyra. London: Routledge, 25-38

Łukasiewicz, J. 1970. Selected Works, ed. L. Borkowski. Amsterdam: North Holland.

McArthur, R.P. 1976. Tense Logic. Dordrecht: Reidel.

McCall, S. 1994. A Model of the Universe. Oxford: Clarendon Press.

Mellor, D.H. 1980. "Necessities and universals in natural laws.” In Science, Belief and Behaviour, ed.

D.H. Mellor, Cambridge: Cambridge University Press, 105-25.

---. 1998. Real Time II. London: Routledge.

---. 2003. "Replies: Change and Time.” In Real Metaphysics: Essays in honour of D.H. Mellor, ed. H.

Lillehammer and G. Rodriguez-Pereyra. London: Routledge, 235-237.

Oaklander, L.N. 1984. Temporal Relations and Temporal Becoming. Lanham: University Press of America.

---. 2002. "Presentism, Ontology and Temporal Experience.” In Time, Reality and Experience, ed. C. Callender. Cambridge: Cambridge University Press, 73-90.

---. 2003. "Presentism: a critique.” In Real Metaphysics: Essays in honour of D.H. Mellor, ed. H.

Lillehammer and G. Rodriguez-Pereyra. London: Routledge, 196-211.

Plantinga, A. 1974. The Nature of Necessity. Oxford: Clarendon Press.

Prior, A.N. 1957. Time and Modality. Oxford: Oxford University Press.

---. 1967. Past, Present and Future. Oxford: Oxford University Press.

---. 1968a. Papers on Time and Tense. Oxford: Oxford University Press.

---. 1968b. “Now.” Noûs, 2 (1968): 101-119.

---. 1970. “The Notion of the Present.” Studium Generale, 23 (1979): 245-8.

---. 1971. Objects of Thought, ed. P.T. Geach and A.J.P. Kenny. Oxford: Clarendon Press.

---. 1996. “A Statement of Temporal Realism.” In Logic and Reality: Essays on the Legacy of Arthur Prior, ed. J. Copeland. 1996. Oxford: Oxford University Press.

Russell, B. 1921. The Analysis of Mind. London: Allen and Unwin.

Schlesinger, G.N. 1980. Aspects of Time. Indianapolis: Hackett. 
Originally published in Canadian Journal of Philosophy, Volume. 36, No. 1, March 2006: 1-24. (Received December 2003; Revised August 2004). It is also chapter 2 of my A Future for Presentism (Oxford University Press, 2006)

(C) Craig Bourne

Smith, P. 2003. "Deflationism: the Facts." In Real Metaphysics: Essays in honour of D.H. Mellor, ed.

H. Lillehammer and G. Rodriguez-Pereyra. London: Routledge, 43-53.

Smith, Q. 1987. "Problems with the New Tenseless Theory of Time.” Philosophical Studies, 52 (1987): 371-92.

---. 1993. Language and Time. Oxford: Oxford University Press.

Tooley, M. 1977. “The Nature of Laws.” Canadian Journal of Philosophy, 7 (1977): 667-98.

---. 1997. Time, Tense, and Causation. Oxford: Oxford University Press.

Wheeler, J.A. 1978. “The 'past' and the 'delayed choice' double-slit experiment." In Mathematical Foundations of Quantum Theory, ed. A. Marlow. New York: Academic Press.

\footnotetext{
${ }^{\mathrm{i}}$ There is a clear partition between tensed and tenseless theories of time: essentially, tensed theories of time assert that in some objective, mind-independent sense or other, the present is privileged, whereas tenseless theories of time assert that all times are real, no one of which is privileged. Thus all tenseless theorists (e.g., Mellor (1981); (1998); Oaklander (1984), Le Poidevin (1991)) are realists about the past, but tensed theorists needn't be, although some are, e.g., Broad (in some of his writings); Gale (1968); Schlesinger (1980); Smith (1993); McCall (1994), and Tooley (1997).)

ii Throughout this paper, 'exists' is meant tenselessly, for to equate 'exists' with 'exists now' renders presentism trivial. The tenseless reading is the only reading that makes presentism a substantial alternative to the tenseless theory, which currently dominates the philosophy of time.

iii As is widely known, relativity theory creates problems for all tensed theories of time, not just presentism. How to reconcile the two cannot be addressed in this paper, but see my (2006) for a proposed solution. Note that this solution is perfectly compatible with the version of presentism I present below.

${ }^{\text {iv }}$ For ease, I shall talk throughout of facts and their constituents as truthmakers. Those sympathetic to particulars as truthmakers can make the relevant changes.

${ }^{\mathrm{v}} \mathrm{I}$ am here assuming the truth-value links generated in linear time. Those who don't accept that $p$ also generates PF $p$ (because they hold that the future branches, say) would still want to hold that $p$ generates
} 
Originally published in Canadian Journal of Philosophy, Volume. 36, No. 1, March 2006: 1-24. (Received December 2003; Revised August 2004). It is also chapter 2 of my A Future for Presentism (Oxford University Press, 2006)

(C) Craig Bourne

FP $p$ and the truth-value links associated with it. My point is that this version of presentism cannot even guarantee that these truth-value links are preserved.

${ }^{\text {vi }}$ The versions of presentism proposed by Bigelow (1996) and Craig (1997), which also pack all of their proposed truthmakers for past- and future-tensed statements into the present, are subject to such criticisms. See Oaklander (2002) for specific criticisms of these versions of presentism, and Oaklander (2003) for criticisms of Craig's later (2000a), (2000b) attempts at defending presentism.

${ }^{\text {vii }}$ Lewis $(1986,204)$ briefly mentions the possibility of holding some kind of ersatz position concerning time. His reason for dismissing it is that 'No man...believes that he has no future; still less does anyone believe that he has no past'. This is ambiguous. On one reading it is plain false: no presentist believes they have a future in the sense of real times that exist later than now. On the other reading, it is true but harmless, for presentists (can) believe that there will be more times to come, even though there are no real times later than our present time $(\operatorname{see} \S \mathbf{I V}(d))$.

${ }^{\text {viii }}$ For the purposes of this paper, I shall take propositions to be primitive abstract objects. However, this is not to say that nothing more can be said about them: they are entities capable of being either true or false, entities to which we can have attitudes (such as beliefs, desires, hopes and fears), and they are capable of representing states of affairs. How they manage to do this is not within the scope of this paper. Being abstract entities, they may raise the understandable question of how we come to grasp them. But I think this worry is misguided. It is no more mysterious than coming to know any truth. Grasping the content of propositions about the concrete world requires interaction only with the concrete world and not with an abstract object.

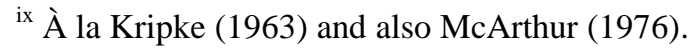

${ }^{\mathrm{x}}$ I take my cue here from Adams (1974) in his analogous discussion of truth simpliciter and truth-at-aworld in the possible worlds debate.

${ }^{\mathrm{xi}}$ I use this truth-condition since $\mu$ is defined as a set of $u$-propositions that is true at that the, thus it is not the case that ' $\sim p$ ' is true iff ' $p$ ' is false, since $p$ does not even appear in that time if ' $p$ ' is false at that time.

xii Thus Russell's hypothesis is harmless to Ersatzer Presentism. The E-relation simply does not hold if the world has just come into existence; so no past-tensed propositions are true, as required.

${ }^{x i i i}$ For a treatment of the complications that arise with numerical quantification, see Bourne (2007). 
Originally published in Canadian Journal of Philosophy, Volume. 36, No. 1, March 2006: 1-24. (Received December 2003; Revised August 2004). It is also chapter 2 of my A Future for Presentism (Oxford University Press, 2006) (C) Craig Bourne

${ }^{\text {xiv }}$ See Bourne (2006) for a treatment of tense operators falling within the scope of the quantifiers.

${ }^{\mathrm{xv}}$ See Bourne (2004) for a treatment of future contingent statements with indeterminate truth-values which is compatible with the laws of non-contradiction and excluded middle.

${ }^{x v i}$ Many thanks to Oren Goldschmidt, Katherine Hawley, Hugh Mellor, Peter Smith and one of the anonymous referees for helpful comments. This paper was first given at the Cambridge Graduate Seminar (April 2001) as 'The Presentist Manifesto', then at the Moral Sciences Club, Cambridge (March 2002) as 'Between Timid and Timbuktoo' and then at Leeds University (February 2004) as 'Real Time III: The Presentist Strikes Back'. Many thanks to those audiences. 